\title{
Efecto del almidón y dos fitorreguladores sobre la germinación de Prosthechea sp.
}

\section{Effect of Starch and Two Phytoregulators on the Germination Process of Prosthechea sp.}

César Ariza

Programa de Ingeniería Agronómica, Facultad de Ciencias Agropecuarias,

Universidad de Cundinamarca, Colombia

https://orcid.org/0000-0002-6983-7621

caariza@ucundinamarca.edu.co

Edwin Deaza

Ingeniero Agrónomo de la Universidad de Cundinamarca Programa de Ingeniería Agronómica, Facultad de Ciencias Agropecuarias,

Universidad de Cundinamarca, Colombia https://orcid.org/0000-0003-3501-4325

edeaza2511@gmail.com

Arlette Gil

M.Sc. en Ciencias Agrarias de la Universidad Nacional de Colombia Programa de Ingeniería Agronómica, Facultad de Ciencias Agropecuarias,

Universidad de Cundinamarca, Colombia https://orcid.org/0000-0001-6536-5877

aigil@ucundinamarca.edu.co

Cristian Orjuela

Programa de Ingeniería Agronómica, Facultad de Ciencias Agropecuarias,

Universidad de Cundinamarca, Colombia https://orcid.org/0000-0001-6133-3472

cristianorjuela92@hotmail.com

Fecha de recepción: 11 de noviembre del 2017

Fecha de aceptación: 1 de junio del 2018

Sugerencia de citación: Ariza, C., Deaza, E., Gil, A., y Orjuela, C. (2018). Efecto del almidón y dos fitorreguladores sobre la germinación de Prosthechea sp. Mutis, 8(2), 37-46, doi: http://dx.doi.org/10.21789/22561498.1403

\section{RESUMEN}

Este artículo aborda la investigación que se realizó para determinar el efecto del almidón y dos reguladores de crecimiento (6-bencilaminopurina, BAP, y ácido naftalenacético, ANA) sobre la germinación de Prosthechea sp., una orquídea cuya población está disminuyendo y en peligro de extinción en San Rafael, zona rural de Fusagasugá (Cundinamarca, Colombia), debido a la deforestación y a la explotación ilegal por parte de sus habitantes. Como alternativa para su propagación, algunas semillas se cultivaron in vitro sobre el medio Murashige y Skoog, suple-

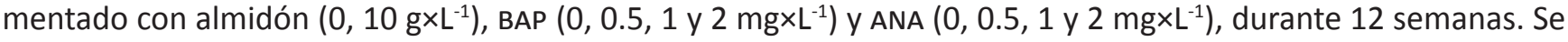
utilizó un diseño al azar con un arreglo factorial de $2 \times 4 \times 4$, con 32 tratamientos y 5 repeticiones. En los resultados 
se observó que los tratamientos suplementados con almidón obtuvieron los mayores valores de germinación,

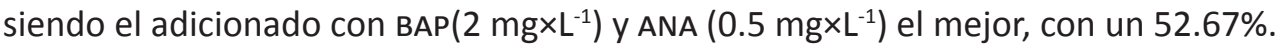

Palabras clave: auxina, citoquinina, in vitro, semillas, orquídeas.

\section{ABSTRACT}

This paper presents the research that was carried out to determine the effect of starch and two growth regulators (6-benzylaminopurine, BAP, and naphthalene acetic acid, ANA) on the germination of Prosthechea sp., an orchid whose population is declining and at risk of extinction in San Rafael, rural area of Fusagasuga (Cundinamarca, Colombia), due to deforestation and illegal exploitation by local inhabitants. As an alternative for its propagation, some seeds were cultivated in vitro on the Murashige and Skoog medium, supplemented with starch $\left(0,10 \mathrm{~g} \mathrm{~L}^{-1}\right)$,

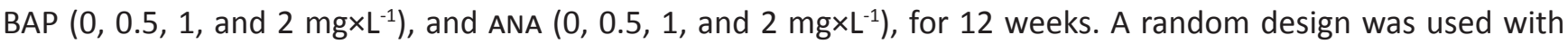
a $2 \times 4 \times 4$ factorial arrangement, with 32 treatments and 5 repetitions. The results showed that the treatments supplemented with starch obtained the highest values of germination, being the one added with BAP $\left(2 \mathrm{mg} \times \mathrm{L}^{-1}\right)$

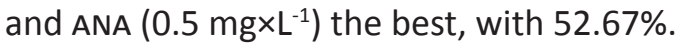

Keywords: Auxin, cytokinin, in vitro, seeds, orchids.

\section{INTRODUCCIÓN}

Colombia es un país diverso en cultura, fauna y flora; en particular, tiene una gran diversidad de orquídeas nativas. Se estima que existen alrededor de 9.000 especies entre los bosques húmedos de Colombia y Ecuador; sin embargo, se reportan aproximadamente 3.000 especies en peligro de extinción (Pérez, Sánchez \& Ortiz, 2009). En Colombia, las orquídeas ocupan el deshonroso primer lugar como la familia de plantas con el mayor número de especies amenazadas (Calderón-Sáenz, 2007). Las especies de los bosques nublados del país tienen doble riesgo debido a sus niveles altos de endemismo y a las tasas elevadas de conversión de sus ecosistemas para actividades como la agricultura y la ganadería; además, se prevé que esta situación se agravará como consecuencia del calentamiento global (Jarvis, 2009).

Prosthechea sp. es una orquídea muy apetecida entre las personas por el color y forma de sus flores, lo cual ha afectado su población debido a la colecta ilegal e indiscriminada y a la paulatina deforestación por parte de los habitantes de las zonas rurales del municipio de Fusagasugá (departamento de Cundinamarca, Colombia). Ante esta situación, es necesario establecer un programa de conservación de orquídeas. En el caso del género Prosthechea, sería pertinente usar la propagación in vitro, teniendo en cuenta que es importante conocer las diferentes concentraciones ade- cuadas de reguladores de crecimiento para producir más plántulas en el menor tiempo posible y disminuir los costos de producción.

Entre las medidas que se han implementado para contrarrestar esta problemática y velar por la conservación de las orquídeas, se encuentran los programas de propagación artificial de especies en peligro de extinción (Arditti \& Ernst, 1993). Por lo tanto, la tecnología de cultivos de tejidos vegetales ofrece una alternativa adecuada para facilitar los trabajos de multiplicación a gran escala y suplir los requerimientos necesarios para los planes de conservación (Gil, Contreras, \& Gutiérrez, 2016).

Knudson (1922) descubrió que las semillas podían ser germinadas en un medio simple con azúcar, lo que revolucionó la propagación y el cultivo de orquídeas. Su trabajo demostró que la germinación de semillas de orquídeas en condiciones in vitro era posible sin la asociación con hongos. Posteriormente, propuso una nueva solución con la adición de nutrientes para la germinación de semillas de orquídeas en 1946 (Martin, 2003). Las aplicaciones del cultivo in vitro de orquídeas son muchas: propagación masiva de plantas -especialmente de difícil propagación o en vías de extinción-, clonación de individuos de características agronómicas muy deseables durante todo el año, obtención de plantas libres de virus, conservación de germoplasmas, producción de nuevos híbridos, mejo- 
ra genética de plantas y germinación de semillas (Soto-Arenas, Solano-Gómez, \&Hágsater, 2007).

Los reguladores de crecimiento vegetal se emplean para promover la división y diferenciación celular. En este sentido, dentro del cultivo in vitro de orquídeas los más utilizados son la citoquinina bencilaminopurina (BAP) y la auxina ácido naftalenacético (ANA). Su uso específico en las etapas de germinación y desarrollo de las semillas en medio in vitro permite aumentar la tasa de germinación y reducir el tiempo de desarrollo de los protocormos, cualidades necesarias para un eficiente método de propagación a gran escala (Rodrigues, Gomes, Pasqual, Almendagna, \& De Assis, 2009). Además, el uso adecuado de nutrientes complejos favorece un mayor crecimiento y desarrollo de algunas especies de orquídeas (Kitsaki, Zygouraki, Ziobora, \& Kintzios, 2004; Yam \& Arditti, 2009; Yong, Ge, Ng \& Tan, 2009).

El objetivo del presente estudio fue evaluar el efecto de la citoquinina BAP, la auxina ANA y el almidón sobre la germinación de las semillas de la orquídea Prosthechea $s p$. , con el fin de ayudar a mitigar la disminución de las poblaciones silvestres de dicha especie.

\section{PROBLEMA DE INVESTIGACIÓN}

A nivel mundial, las orquídeas son conocidas como las flores más raras del reino vegetal debido a su complejidad morfológica y a la taxonomía de cada especie. Esto resulta en su admiración y fascinación, lo que ocasiona su sobrexplotación, afectando la conservación y preservación de estas plantas, ya que se convierte en un negocio muy lucrativo para los recolectores por su valor comercial. La propagación de la familia Orquidaceae es muy compleja y limitada porque posee semillas diminutas con un embrión simple carente de endospermo, lo cual dificulta su germinación ex vitro. Esto impide su comercialización a gran escala, por lo que se extrae abruptamente del hábitat de desarrollo, generando así un desequilibrio en el ecosistema (De la Nova, Oria, Casadesus, \& Gómez, 1998).

Solamente del 2 al $5 \%$ de las semillas de orquídeas germinan de forma natural (Rao, 1997) y, si lo hacen, se toman un largo tiempo. Además, cualquier disturbio en el hábitat o ambiente físico puede destruir la totalidad de la población (Pant \& Thapa, 2012). Las orquídeas se caracterizan por tener semillas muy pe- queñas y numerosas, comúnmente llamadas semillas polvo, de considerable variación, que poseen una escasa reserva de nutrientes para germinar. El número de semillas puede variar de 13.000 a 4.000 .000 por cápsula. Una semilla de orquídea mide de 0,25 a 1,2 $\mathrm{mm}$ de largo y de 0,009 a 0,27 mm de ancho, y su rango de peso varía de 0,3 a $14 \mu \mathrm{g}$ (Arditti \& Ghani, 2000). Estas semillas están formadas por un embrión de pocas células (entre 100 y 200) cubiertas por una testa muy dura (Mitchell, 1989).

En condiciones naturales, las semillas requieren la presencia e infección de un hongo simbionte que les proporcione una fuente de carbohidratos y los nutrientes necesarios para el proceso de germinación (Barba, Luna \& Romero, 2001). Este hongo ayuda a las plántulas jóvenes de orquídeas a sobrevivir en campo con reservas alimenticias limitadas y actúa a manera de endospermo exógeno, puesto que aporta los nutrientes necesarios en los primeros estadios de la germinación (Rasmussen, 1995).

La interacción micorriza-orquídea es un tema que ha sido ampliamente estudiado a nivel mundial (Clements, 1987). Diversos estudios han demostrado que, en general, las orquídeas epífitas son específicas en la interacción con las micorrizas (Lee, Taylor y Bruns, 1997) y que su especificidad, especialmente en las especies tropicales, puede ser variable (Otero \& Bayman, 2009).

La germinación de las semillas de Prosthechea sp. es variable en el tiempo, iniciando con la imbibición y posterior protrusión radicular. Posteriormente se forma una esfera de células fotosintéticamente activas denominadas protocormo, que permitirá el desarrollo de pelos radicales y la aparición de hojas (Roy, Patel, Patel, Sajeev, \& Deka, 2011). Los tiempos estimados para cada fase de desarrollo de las orquídeas bajo condiciones in vitro son inciertos, porque varían de acuerdo con el medio de cultivo, la especie y las condiciones ambientales (Pierik, 1990).

Según Pierik (1990), la germinación de las semillas de orquídea inicia cuando el embrión absorbe agua a través de la testa, aumentando su volumen. Después, empieza la división celular y el embrión rompe la cubierta seminal. A continuación, se forma una estructura de tipo protocormo a partir del agregado de células, y sobre aquel puede distinguirse un meristemo del vástago. Tan pronto como inicia la 
diferenciación de órganos (meristemo del vástago en un lado y rizoides en el otro), comienza un periodo de crecimiento intenso. Si el protocormo está a la luz, adquiere un color verde $y$, al mismo tiempo, se desarrollan las hojas. Como resultado de la producción de clorofila, la planta se vuelve autótrofa. Más tarde, las primeras raíces auténticas se forman endógenamente, el protocormo y los rizoides (pelos radicales) pierden su función nutritiva y desaparecen. Los tiempos estimados para cada fase bajo condiciones in vitro son inciertos porque varían de acuerdo con el medio de cultivo, la especie y las condiciones ambientales.

Las orquídeas fueron las primeras plantas que se propagaron in vitro a partir de la siembra de semillas, de manera simbiótica y asimbiótica o clonalmente al introducirse la técnica de cultivo de meristemos para la propagación vegetativa. Dada la importancia hortícola y comercial de las orquídeas, se han desarrollado diversos métodos de propagación, tanto sexual, a través de semillas, como asexual, mediante el cultivo de segmentos vegetativos (Ávila-Díaz, \& Salgado, 2006). Para que la germinación se lleve a cabo se deben cumplir tres condiciones: primero, la semilla debe ser viable; segundo, la semilla debe estar bajo condiciones ambientales adecuadas; y tercero, se debe superar cualquier condición de dormancia, causada por reguladores de crecimiento que inhiben la germinación, o contar con embriones inmaduros (Pedroza-Manrique, Fernandez-Lizarazo, \& Suarez-Silva, 2005).

La propagación natural de las orquídeas se dificulta porque sus semillas son diminutas y carecen de endospermo. Por esta razón, requieren de la interacción con hongos micorrízicos que permiten la germinación de las semillas (Arditti, 1984). Experimentos desarrollados por Knudson (1922) en especies de Cattleya, llevaron a afirmar que las semillas pueden germinar sin la acción del hongo, utilizando azúcares simples y nutrientes en el medio de cultivo. Se han desarrollado metodologías de germinación asimbiótica bajo condiciones in vitro (Arditti \& Ernst, 1993; Steele, 2007). La germinación de semillas de orquídeas de manera asimbiótica permite conservarlas de manera senciIla mediante diversos métodos de micropropagación (Shimasaki \& Uemoto, 1991). Una de las cuestiones básicas de la siembra asimbiótica es la desinfección adecuada de frutos y semillas para lograr cultivos libres de contaminación (Billard, Dalzotto, \& Lallana, 2014). Una de las cuestiones básicas en la siembra asimbiótica es la desinfección adecuada de frutos y semillas para lograr cultivos libres de contaminación (Billard, Dalzotto \& Lallana, 2014).

En el cultivo de orquídeas es muy común la utilización del medio nutritivo Murashige y Skoog (MS), formulado por los científicos Toshio Murashige y Folke Skoog en 1962. Este medio de cultivo proporciona a las semiIlas los 17 nutrientes esenciales -tanto micronutrientes como macronutrientes- para la mayoría de las plantas, a fin de desplazar el papel del hongo en la simbiosis (Roca, Nolt, Mafla, Roa, \&Reyes, 1991; Taiz \& Zeiger, 1998). Por esta razón se eligió el medio Murashige y Skoog (1962), ya que contiene una formulación básica que sirve de fuente de nutrientes a una gran variedad de plantas (Hurtado \& Merino, 1987; Pierik, 1990).

En el crecimiento de los tejidos existe un efecto indirecto entre el $\mathrm{pH}$ y el tipo de fuente de nitrógeno, pues los medios con un $\mathrm{pH}$ por debajo de 5 toman nitratos, y en aquellos con un pH de 5 a 5,5 los callos prefieren amonio o nitratos. Por otro lado, el potasio es necesario para la división celular, la síntesis de proteínas, la producción de clorofila y la reducción de nitratos. Los niveles de $\mathrm{K}^{+}$in vitro difícilmente representan un problema, pero hay ciertas especies que son sensibles a sus altos niveles (Bhojwani \& Razdan, 1996).

\section{MATERIALES Y MÉTODOS}

\section{Material vegetal}

En la reserva natural de San Rafael (Fusagasugá, Cundinamarca), ubicada a 4023'32" LN (latitud norte) y 74018' 48" LW (longitud oeste), a una altitud de 1.909 $\mathrm{m}$ s. n. m., con temperatura media de $17 \stackrel{\circ}{ } \mathrm{C}$, humedad relativa media de $85 \%$ y precipitación anual de $1.250 \mathrm{~mm}$, se situó una población de plantas del género Prosthechea sobre forofitos de caucho (Ficus sp.). De esta población se obtuvieron 8 cápsulas con una madurez avanzada y un diámetro entre 2 y $3 \mathrm{~cm}$ (figura 1).

\section{Protocolo de esterilización}

Las cápsulas se llevaron al laboratorio de cultivo de tejidos vegetales de la Universidad de Cundinamarca para su procesamiento en condiciones asépticas. Estas se lavaron superficialmente con abundante agua corriente 
Figura 1. Cápsula de Prosthechea sp.

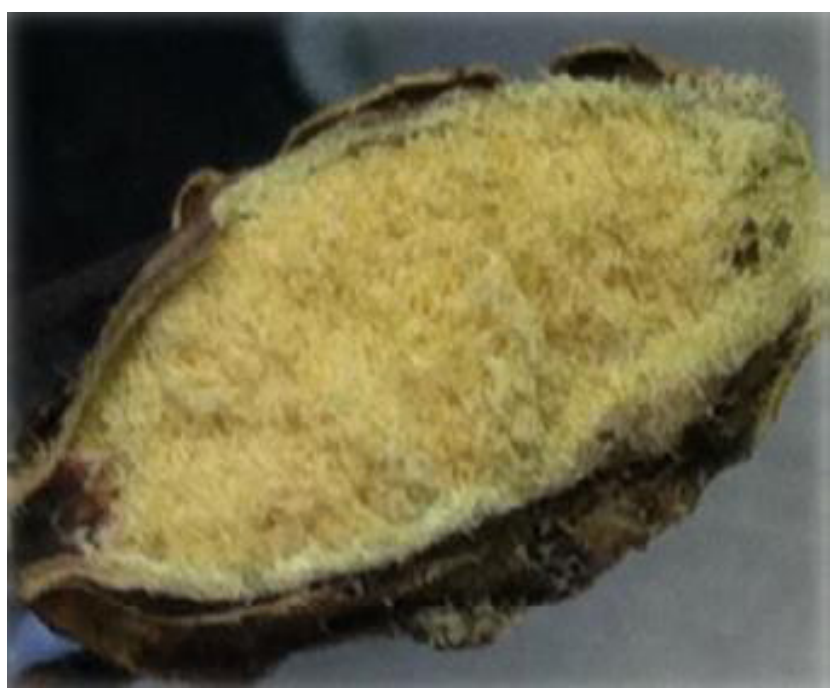

Fuente: Deaza \& Orjuela (2017)

y jabón antibacterial (Protex ${ }^{\circledR}$ ). Después, en la cámara de flujo laminar horizontal (Flow $85 \mathrm{H}^{\circledR}$ ), se sumergieron las cápsulas durante 10 minutos en una solución de hipoclorito de sodio al $5 \%$, se lavaron dos veces con agua destilada estéril y luego se colocaron en inmer- sión en alcohol al 70 \% por 1 minuto. Posteriormente, se escurrieron sobre servilletas estériles $y$, finalmente, se flamearon con el mechero Bunsen. Para extraer la semilla, se hizo un corte longitudinal en la cápsula con la ayuda de unas pinzas y un bisturí previamente esterilizados. La semilla de tipo polvoso fue esparcida sobre la superficie de medio de cultivo MS en frascos de vidrio (dimensiones) con un volumen de $250 \mathrm{~mL}$.

\section{Metodología}

Se utilizó el medio salino básico Msdesarrollado por Murashige y Skoog, suplementado con diferentes concentraciones de almidón -fécula de maíz-

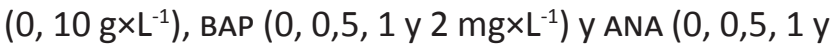

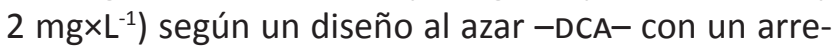
glo factorial de $2 \times 4 \times 4$, con 32 tratamientos y 5 repeticiones (tabla 1). La unidad experimental correspondió a cada frasco de vidrio de $250 \mathrm{~mL}$, con el fin de evaluar su efecto sobre la germinación. El cultivo se realizó bajo condiciones in vitro durante 12 semanas bajo un régimen lumínico de 12 horas de luz -luz blanca fría- y 12 horas de oscuridad, con una temperatura promedio de $25^{\circ} \mathrm{C}$.

Tabla 1. Tratamientos utilizados en la germinación de Prosthechea sp.

\begin{tabular}{|c|c|c|c|}
\hline Tratamiento & Almidón $\left({\left.\mathrm{g} \times \mathrm{L}^{-1}\right)}^{-1}\right.$ & BAP $(m g \times L-1)$ & ANA $\left(\mathrm{mg} \times \mathrm{L}^{-1}\right)$ \\
\hline 1 & 0 & 0,5 & 0 \\
\hline 2 & 0 & 1 & 0 \\
\hline 3 & 0 & 2 & 0 \\
\hline 4 & 0 & 0 & 0,5 \\
\hline 5 & 0 & 0,5 & 0,5 \\
\hline 6 & 0 & 1 & 0,5 \\
\hline 7 & 0 & 2 & 0,5 \\
\hline 8 & 0 & 0 & 1 \\
\hline 9 & 0 & 0,5 & 1 \\
\hline 10 & 0 & 1 & 1 \\
\hline 11 & 0 & 0 & 2 \\
\hline 12 & 0 & 0,5 & 2 \\
\hline 13 & 0 & 1 & 2 \\
\hline 14 & 0 & 2 & 2 \\
\hline 15 & 0 & 1 & 0 \\
\hline 16 & 10 & 0,5 & 0 \\
\hline 17 & 10 & 1 & 0 \\
\hline 18 & 10 & 2 & 0 \\
\hline 19 & 10 & 0 & 0,5 \\
\hline 20 & 10 & 0,5 & 0,5 \\
\hline 21 & 10 & 1 & 0,5 \\
\hline 22 & 10 & 2 & 0,5 \\
\hline 23 & 10 & 0 & 1 \\
\hline 24 & 10 & 0,5 & 1 \\
\hline 25 & 10 & 1 & 1 \\
\hline 26 & 10 & 2 & 1 \\
\hline 27 & 10 & 0 & 2 \\
\hline 28 & 10 & 0,5 & 2 \\
\hline 29 & 10 & 1 & 2 \\
\hline 30 & 10 & 2 & 2 \\
\hline 31 & 0 & 0 & 0 \\
\hline 32 & 10 & 0 & 0 \\
\hline
\end{tabular}

Fuente: elaboración propia. 
Cada 7 días se observaron tres unidades experimentales con el estereoscopio; en cada una se evaluó la mitad del área de la base del frasco y se examinó el número de semillas germinadas como variable para luego proceder a llevarlas a porcentaje de germinación, de acuerdo con la fórmula:

\section{\%germinación = número de semillas germinadas/nú- mero total de semillas evaluadas}

Los datos obtenidos se sometieron a un análisis de varianza (ANOVA) y a la prueba de Fisher LSD ( $\mathrm{P} \leq 0,05)$, utilizando el programa Info Stat -versión libre-.

\section{RESULTADOS Y DISCUSIÓN}

La fase de germinación se evaluó desde la primera semana después de la siembra de las semillas de Pros- thechea sp. hasta la séptima semana, calculando el porcentaje de germinación de semillas de acuerdo con las observaciones del material vegetal en el laboratorio (figura 2 ).

En el tratamiento 22, con el medio enriquecido con almidón $\left(10 \mathrm{~g} \times \mathrm{L}^{-1}\right)+\mathrm{BAP}\left(2 \mathrm{mg} \times \mathrm{L}^{-1}\right)+\mathrm{ANA}\left(0,5 \mathrm{mg}^{\mathrm{L}-}\right.$ $\left.{ }^{1}\right)$, y el tratamiento 30 , con el medio suplementado con almidón $\left(10{\left.\mathrm{~g} \times \mathrm{L}^{-1}\right)}^{-1}\right.$ BAP $\left(2 \mathrm{mg} \times \mathrm{L}^{-1}\right)+\mathrm{ANA}\left(2 \mathrm{mg} \times \mathrm{L}^{-}\right.$ $\left.{ }^{1}\right)$, se obtuvieron los mayores valores de porcentaje de germinación: 52,67 y 50,67\%, respectivamente (figura 3); estos tratamientos estaban suplementados adicionalmente con almidón como fuente de carbono. Por otro lado, la germinación más baja se evidenció en los tratamientos con ausencia de este componente, como los tratamientos 8,1 y 12 , cuyos porcentajes de germinación de semillas fueron: 8,7 y $5 \%$, respectivamente.

Figura 2. Semillas germinadas de Prosthechea sp. bajo condiciones in vitro.

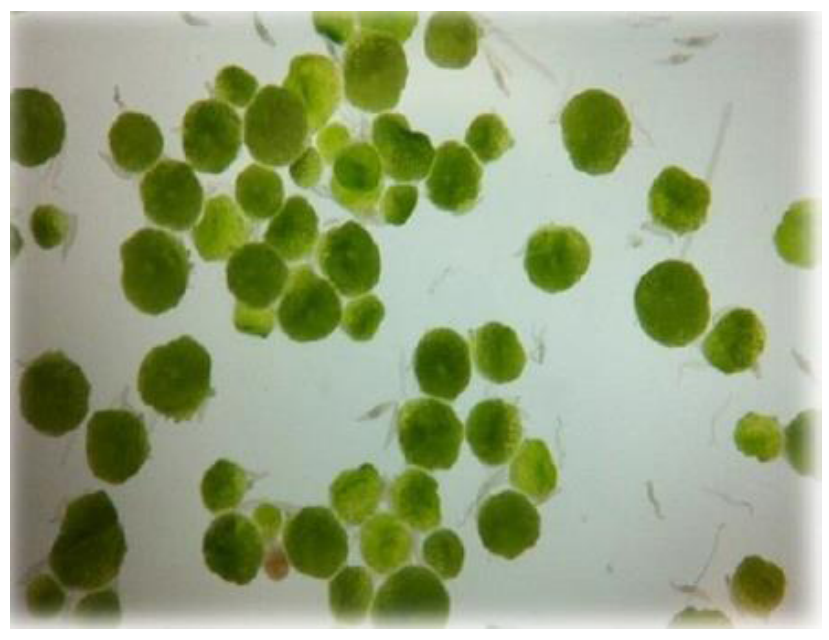

Fuente: Deaza \& Orjuela (2017).

El medio MS se utiliza con frecuencia en diversas especies de orquídeas $y$, al suplementarse con distintas concentraciones de reguladores de crecimiento como BAP y ANA en interacción con almidón, presenta efectos favorables sobre la germinación de las semillas. En este sentido, Arditti y Ernst (1993) concluyen que los porcentajes de germinación alcanzados en orquídeas epífitas tropicales sobre un medio asimbiótico son superiores a $50 \%$; mientras que Kalimuthu, Senthilkumar y Vijayakumar (2007) describen una regeneración in vitro satisfactoria de Oncidium sp. al adi-

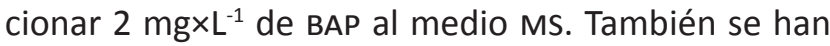

obtenido resultados favorables con otros medios de cultivo enriquecidos con reguladores de crecimiento, lo cual se evidencia en estudios como el de Hossain, Sharma, Teixeira da Silva y Pathak (2010), donde obtuvieron aproximadamente un $100 \%$ de germinación de las semillas de orquídea Cymbidium giganteum Wall. ex Lindl con los medios Mitra y Phytamax suplemen-

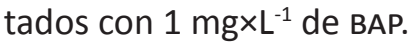

Algunos autores han reportado que el uso de ácido naftalenacético (ANA) sobre la germinación de orquídeas no es favorable, porque este se utiliza para 
Figura 3. Porcentaje de germinación de semillas de Prosthechea sp. bajo condiciones in vitro.

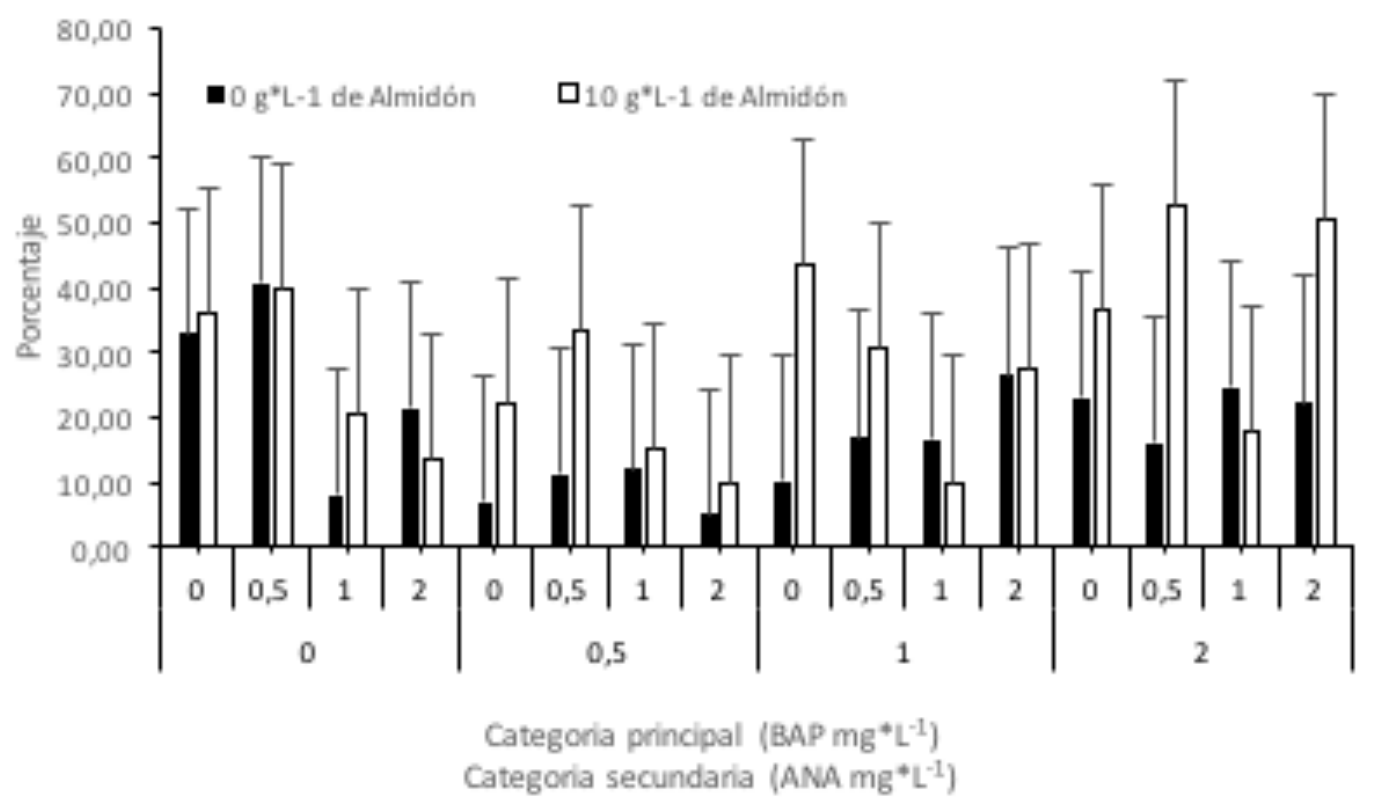

Fuente: elaboración propia.

estimular la formación de raíces adventicias (Derkx \& Karssen, 1993; Hilhorst \& Karssen, 1989; Ikuma \& Thimann, 1963; Perry \& Metzger, 1980; Yang et al., 1999); por lo tanto, es posible que no afecte la germinación de Prosthechea sp. Para este caso, cabe citar el estudio realizado por Paudel, Pradhan y Pant (2012) con semillas de la orquídea Esmeralda clarkei Rchb.f., donde obtuvieron una mayor germinación al enrique-

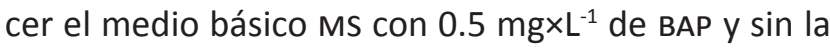
adición de ANA.

Los resultados obtenidos en esta investigación coinciden con los de Parmar y Pant (2016), quienes en estudios desarrollados con la orquídea Coelogyne stricta

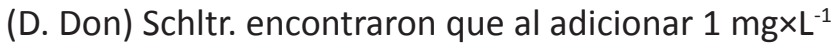

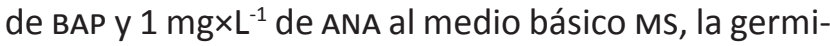
nación de semillas incrementó, inició a las 7 semanas de cultivo y se formaron plántulas después de 23 semanas de cultivo, de manera que ambos fitorreguladores indujeron la formación de raíces. En otro estudio con la orquídea Coelogyne flaccida Lindl., Parmar y Pant (2015) encontraron que al suplementar el me-

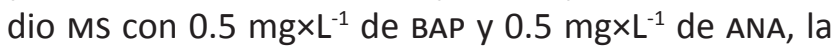
germinación inició 6 semanas después de la siembra en el medio.

Estos resultados también concuerdan con los que obtuvieron Bazand, Otroshy, Fazilati, Piri y Mokhta- ri (2014) con la orquídea Phalaenopsis amabilis (L.) Blume, donde el mayor porcentaje de germinación $(83,75 \%)$ se presentó al adicionar una concentra-

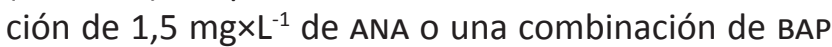

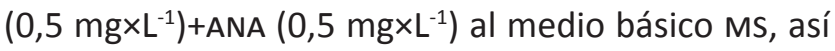
como con los que obtuvieron Seeja, Sreekumar, Biju y Arya (2018), quienes encontraron que la germinación de semillas de Spathoglottis albida Kraenzl. fue mayor $(93 \%)$ al utilizar el medio Ms enriquecido con 1,5

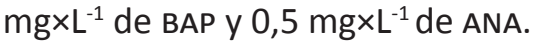

Por último, tras observar que la ausencia de almidón no favoreció la germinación de semillas de Prosthechea sp. bajo condiciones in vitro, se puede afirmar que su uso genera un mayor porcentaje de germinación por cuanto la fécula de maíz aporta vitaminas a la semilla además de glutamina, un aminoácido esencial para el crecimiento de embriones inmaduros por ser una importante fuente de nitrógeno (Pierik, 1990), que probablemente supla los requerimientos de carbohidratos externos necesarios para la germinación de las semillas de orquídeas. 


\section{CONCLUSIÓN}

El medio de cultivo Murashige y Skoog (MS) su-

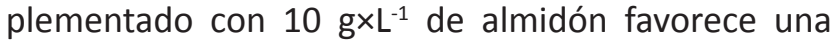
mayor germinación de las semillas de la orquídea Prosthechea sp., de igual manera, el uso de $2 \mathrm{mg} \mathrm{L}^{-1}$ de bencilaminopurina (BAP) y 0,5 mg×L-1 de ácido naftalenacético (ANA) potencia su germinación, por lo tanto, se recomienda su uso combinado en esta especie vegetal.

\section{REFERENCIAS}

Arditti, J. (1984). An history of orchid hybridization, seed germination and tissue culture. Botanical Journal of the Linnean Society, 89(4), 359-381.

Arditti, J., \& Ernst, R. (1993). Micropropagation of orchids. New York, United States: John Wiley-Sons, Inc.

Arditti, J., \& Ghani, A. K. (2000). Tansley Review No. 110. Numerical and physical properties of orchid seeds and their biological implications. The New Phytologist, 145(3), 367-421.

Ávila-Díaz, I., \& Salgado, G. R. (2006). Propagación y mantenimiento in vitro de orquídeas mexicanas, para colaborar en su conservación. Biológicas, 8 , 138-149.

Barba, A., Luna, B., \& Romero, J. (2001). Micropropagación de plantas. México, D. F., México: Trillas.

Bazand, A., Otroshy, M., Fazilati, M., Piri, H., \& Mokhtari, A. (2014). Effect of plant growth regulators on seed germination and development of protocorm and seedling of Phalaenopsis amabilis (L.) Blume (Orchidaceae). Annual Research \& Review in Biology, 4(24), 3962-3969.

Bhojwani, S., \& Razdan, M. (1996). Plant tissue culture: Theory and practice, a revised edition. Amsterdam, Netherlands: Elsevier.

Billard, C. E., Dalzotto, C. A., \& Lallana, V. H. (2014). Desinfección y siembra asimbiótica de semillas de dos especies y una variedad de orquídeas del género Oncidium. Polibotánica, 38, 69-81.
Calderón-Sáenz, E. (Ed.). (2007). Libro rojo plantas de Colombia. Volumen 6: Orquídeas, primera parte. Serie libros rojos de especies amenazadas de Colombia. Bogotá, Colombia: Instituto Alexander von Humboldt-Ministerio de Medio Ambiente, Vivienda y Desarrollo Territorial.

Clements, M. A. (1987). The symbiotic method of orchid seed germination. Progress on Australasian epiphytes. Proceedings of the World Orchid Hiroshima Symposium. Japan, Hiroshima.

Clements, M. A. (1988). Orchid mycorrhizal associations. Lindleyana, 3, 73-86.

De la Nova, B. M., Oria, A., Casadesus, L., \& Gómez, M. (1998). Aislamiento, caracterización e inoculación con endomicorrizas orquideales en especies de orquídeas. La Habana, Cuba: Instituto Nacional de Ciencias Agrícolas, Universidad de La Habana.

Derkx, M. P. M., \& Karssen, C. M. (1993). Changing sensitivity to light and nitrate but not to gibberellins regulates seasonal dormancy patterns in Sisymbrium officinale seeds. Plant, Cell \& Environment, 16(5), 469-479.

Gil, A., Contreras, D., \& Gutiérrez, L. (2016). Establecimiento in vitro de protocormos de Prosthechea sp. bajo diferentes concentraciones de ácido naftalenacético. Mutis, 6(1), 6-15. doi: $10.21789 / 22561498.1108$

Hilhorst, H. W. M., \& Karssen, C. M. (1989). The role of light and nitrate in seed germination. In R. B. Taylorson (Ed.), Recent advances in the development and germination of seeds (pp. 191205). New York, United States: Plenum Press.

Hossain, M. M., Sharma, M., Teixeira da Silva, J. A. , \& Pathak, P. (2010). Seed germination and tissue culture of Cymbidium giganteum Wall. ex Lindl. Scientia Horticulturae, 123(4), 479-487. doi: 10.1016/j.scienta.2009.10.009

Hurtado, M. D. V., \& Merino, M. M. E. (1987). Cultivo de tejidos vegetales. México, D. F., México: Editorial Trillas, S. A. de C. V.

Ikuma, H., \& Thimann, K. (1963). Activity of gibberellin ' $D$ ' on the germination of photosensitive lettuce seeds. Nature, 197, 1313-1314. 
Jarvis, A. (2009). La conservación de orquídeas. Congreso sobre biodiversidad y cambio climático. Contraloría Nacional de Colombia, Colombia.

Kalimuthu, K., Senthilkumar, R., \& Vijayakumar, S. (2007). In vitro micropropagation of orchid, Oncidium sp. (Dancing Dolls). African Journal of Biotechnology, 6(10), 1171-1174.

Kitsaki, C. K., Zygouraki, S., Ziobora, M., \& Kintzios, S. (2004). In vitro germination, protocorm formation and plantlet development of mature versus immature seeds from several Ophrys species (Orchidaceae). Plant Cell Reports, 23(5), 284-290.

Knudson C. (1922). Nonsymbiotic germination of orchid seeds. Botanical Gazette, 73, 1-25.

Lee Taylor, D., \& Bruns, T. D. (1997). Independent, specialized invasions of ectomycorrhizal mutualism by two nonphotosynthetic orchids. Proceedings of the National Academy of Sciences of the United States of America, 94(9), 4510-4515.

Martin, K. P. (2003). Clonal propagation, encapsulation and reintroduction of Ipsea malabarica (Reichb. f.) J. D. sinensis var. amoena in vitro. Mycological Research, 97(6), 746-752.

McKendrick, S. L., Leake, J. R., Lee Taylor, D., \& Read, D. J. (2002). Symbiotic germination and development of the myco-heterotrophic orchid Neottia nidusavis in nature and its requirement for locally distributed Sebacina spp. New Phytologist, 154(1), 233-247.

Mitchell, R. (1989). Growing hardy orchids from seeds at Kew. Plantsman, 11, 152-169.

Murashige, T. y Skoog, F. (1962). A revised medium of rapid growth and bio assays with tobacco tissue cultures. Physiologia Plantarum, 15(3), 473-497.

Otero, J. T., \& Bayman, P. (2009). Symbiotic vs. asymbiotic seed germination in epiphytic orchids. Acta Agronómica, 58(4), 270-276.

Pant, B., \& Thapa, D. (2012). In vitro mass propagation of an epiphytic orchid, Dendrobium primulinum Lindl. through shoot tip culture. African Journal of Biotechnology, 11(42), 9970-9974. doi: 10.5897/ AJB11.3106
Parmar, G., \& Pant, B. (2015). In vitro seed germination and seedling development of Coelogyne flaccida Lindl. (Orchidaceae). Advances in Forestry Science, 2(4), 85-88.

Parmar, G., \& Pant, B. (2016). In vitro seed germination and seedling development of the orchid Coelogyne stricta (D. Don) Schltr. African Journal of Biotechnology, 15(5), 105-109. doi: 10.5897/ AJB2015.14870

Paudel, M., Pradhan, S., \& Pant, B. (2012). In vitro seed germination and seedling development of Esmeralda clarkei Rchb. f. (Orchidaceae). Plant Tissue Culture and Biotechnology, 22(2), 107-111.

Pedroza-Manrique, J., Fernandez-Lizarazo, C., \& Suarez-Silva, A. (2005). Evaluation of the effect of three growth regulators in the germination of Comparettia falcata seeds under in vitro conditions. In Vitro Cellular \& Developmental Biology. Plant, 41(6), 838-843.

Pérez, O., Sánchez, E., \& Ortiz, P. (2009). Inventario orquideológico de la Reserva Bosque de Yotoco, Valle del Cauca. Acta Agronómica, 58(3), 189-196.

Perry, L. M., \& Metzger, J. (1980). Medicinal plants of east and southeast Asia: attributed properties and uses. Cambridge, Estados Unidos: MIT Press.

Pierik, R. L. (1990). Cultivo in vitro de las plantas superiores. Madrid, España: Mundi-Prensa.

Rao, A. N. (1997). Tissue culture in Orchid Industry. In J. Reinert \& Y. P. S. Bajaj (Eds.), Applied and Fundamental aspects of Plant Cell, Tissue and Organ Culture. New Delhi, India: Narosa Publishing House.

Rasmussen, H. N. (1995). Terrestrial orchids. From seeds to mycotrophic plants. Cambridge, United Kingdom: Cambridge University Press.

Roca, W. M., Nolt, B., Mafla, G., Roa, J. C., \& Reyes, R. (1991). Eliminación de virus y propagación de clones en la yuca (Manihot esculenta Crantz). En W. M. Roca \& L. A. Mroginski (Eds.), Cultivo de tejidos en la agricultura: fundamentos y aplicaciones (pp. 403-421). CIAT. 
Rodrigues, J., Gomes, A., Pasqual, M., Almendagna, F., \& De Assis, F. (2009). Concentrações de sais do meio Knudson $\mathrm{C}$ e de ácido giberélico no crescimento in vitro de plântulas de orquídea. Ciência Rural, 39(3), 772-777.

Roy, A. R., Patel, R. S., Patel, V. V., Sajeev, S., \& Deka, B. (2011). Asymbiotic seed germination, mass propagation and seedling development of Vanda coerulea Griff ex. Lindl. (Blue Vanda): an in vitro protocol for an endangered orchid. Scientia Horticulturae, 128(3), 325-331.

Seeja, G., Sreekumar, S., Biju, C. K., \& Arya, K. (2018). Inbreeding and in vitro seed germination in Spathoglottis albida Kraenzl. Journal of Agriculture and Veterinary Science, 11(1), 14-20. doi: $10.9790 / 2380-1101031420$

Shimasaki, K., \& Uemoto, S. (1991). Rhizome induction and plantlet regeneration of Cymbidium goeringii from flower bud cultures in vitro. Plant cell, Tissue and Organ Culture, 25(1), 49-52.

Soto-Arenas, M., Solano Gómez, R., \& Hágsater, E. (2007). Risk of extinction and patterns of diversity loss in Mexican orchids. Lankesteriana, 7(1-2), 114-121.

Steele, W. K. (2007). Propagation protocol for ram's head lady's slipper (Cypripedium arietinum). Native Plants Journal, 8(1), 58-64.

Taiz, L., \& Zeiger, E. (1998). Plant physiology. Sunderland, England: Sinanuer Associates, Inc.

Yam, T. W., \& Arditti, J. (2009). History of orchid propagation: a mirror of the history of biotechnology. Plant Biotechnology Reports, 3(1). doi: 10.1007/s11816-008-0066-3

Yang, J., Lee, H. J., Shin, D. H., Oh, S. K., Seon, J. H., Paek, K. Y., \& Han, K. H. (1999). Genetic transformation of Cymbidium orchid by particle bombardment. Plant Cell Reports, 18(12), 978-984.

Yong, J. W., Ge, L., Ng, Y. F., \& Tan, S. N. (2009). The chemical composition and biological properties of coconut (Cocos nucifera L.) water. Molecules, 14(12), 5144-5164. 